\title{
Negotiating anthropomorphism in the Ai-Da robot
}

\author{
Bojana Romic ${ }^{1}$ (D)
}

Accepted: 25 June 2021 / Published online: 30 July 2021

(c) The Author(s) 2021

\begin{abstract}
The central interest of this paper is the anthropomorphic social robot Ai-Da (Aidan Meller Gallery/Oxford University), perceived as an actor in the interplay of cultural and representational gestures. These gestures determine how this robot is presented - that is, how its activities are articulated, interpreted and promoted. This paper criticises the use of a transhistorical discourse in the presentational strategies around this robot, since this discourse reinforces the so-called "myth of a machine". The discussion focuses on the individuation and embodiment of this drawing robot. It is argued that the choice to provide Ai-Da with an evocative silicone face, coupled with an anthropomorphic body, is a socio-political decision that shapes public imaginaries about social robots in general.
\end{abstract}

Keywords Robot $\cdot$ Anthropomorphism $\cdot$ Ai-Da $\cdot$ Robotic art $\cdot$ Drawing robot $\cdot$ Creativity

\section{Introduction}

The research on anthropomorphism in social robots has received substantial attention [1-6]. Notably, Fong, Nourbakhsh, and Dautenhahn [7] provide a taxonomy of social robots and address anthropomorphism as a feature that helps the general public connect to robots, as it evokes users' feelings and elicits nurturing behaviour. I adopt their definition of a social robot as a "socially interactive robot, for which social interaction plays a key role" ([7] p. 145), and this definition excludes teleoperated robots. I define a robot as an embodied artificial agent that can perform a series of actions automatically.

The link between appearance and agency in an anthropomorphic social robot is a curious one, not only due to the uncanny valley effect, ${ }^{1}$ but also because it provokes some epistemological questions that prompt us to revisit the repository of cultural imaginings revolving around the figure of a

The research is supported by the Strategy Group for EU-Coordination, represented by Vinnova.

Bojana Romic

bojana.romic@mau.se

1 School of Arts and Communication \& MEDEA, Malmö

University, Bassänggatan 2, 21119 Malmö, Sweden

${ }^{1}$ Masahiro Mori created a graph that shows how the sense of eeriness is enacted when experiencing an object or a robot that looks very human-like though not exactly the same. This sense increases with the unexpected behaviour of such an object or a robot [8]. robot $[5,9,10]$. In this paper, I observe a social robot from a holistic perspective, arguing that what the robot looks like (i.e., embodiment) and what the robot does (i.e., actions) are the features that shape its social presence and channel imaginings about social robots [11]. Additionally, the robot that I focus on- $A i-D a$-is involved in the production of culture and belongs to a broader register of "drawing robots". It must be noted, however, that in a broad sense, all robots participate in the production of culture, because they are embedded in the social fabric and enable and sustain relationships and knowledge sharing. The robots that I mention in this paper participate in the production of artefacts in the domain of visual arts, with a special focus on drawing robots.

I accept Hayles' (1999; cf. [12]) assertion that physical embodiment is contextual, as it is interwoven with aspects of culture, place, time and physiology. This view of situated physical embodiment and its relation to agency rejects Cartesian mind/body dualism. Therefore, my approach to performativity and embodiment should be observed as two sides of the same coin, both shaping experiences about the drawing robots.

I further acknowledge Winner's [13] assumption that all technologies are inherently political, and I attempt to explore this statement using the Ai-Da robot as a case study. Using two pivotal points of investigation, individuation and embodiment, I embark on an inquiry that aims to answer this question: 


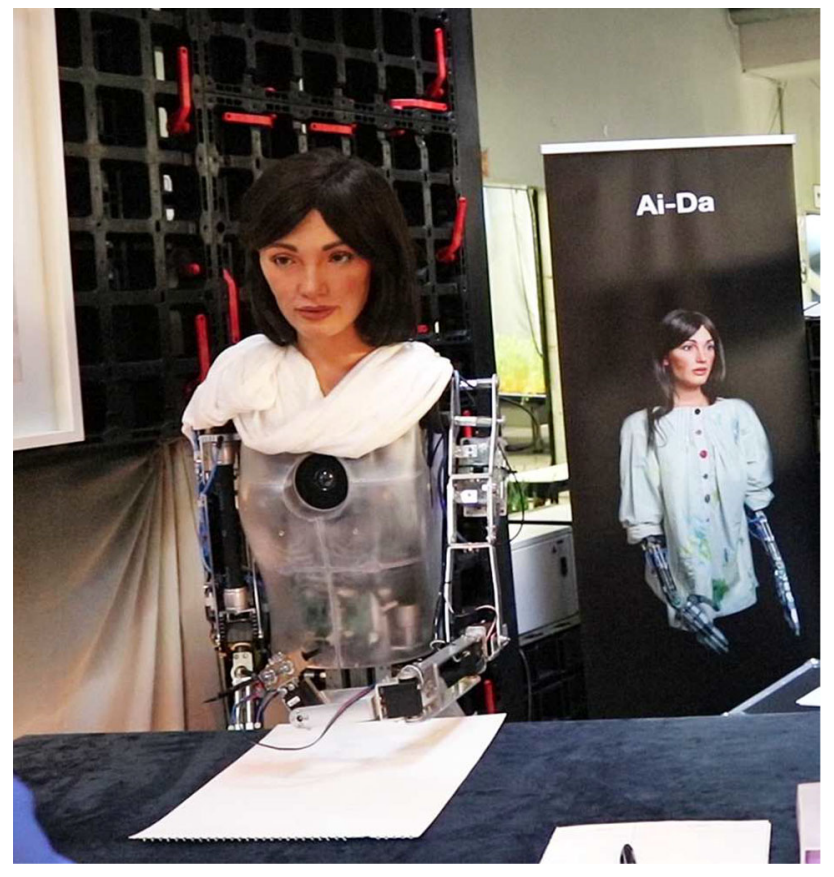

Fig. 1 Ai-Da at Ars Electronica Festival, Linz, 2019. Photo: Bojana Romic

How anthropomorphism and transhistorical discourse affect the political presence of the Ai-Da robot?

I will use discourse analysis to address the communicational strategy used by Aidan Meller, who finances the project and promotes the robot. The analysis will help the process of unpackinxg the hidden meanings used in this promotional strategy.

In the following section, I provide a short historical account of the machines invested in cultural production. I then present the transhistorical view on artistic production and its critique from the art-historical perspective [1]. Next, I discuss the process of individuation and embodiment, relying mainly on Suchman's [6,11] and Knox's [14] inquiries that include a feminist perspective. I conclude with some recommendations.

As for limitations, I do not evaluate the artistic quality of the artefacts created by Ai-Da.

\section{About Ai-Da}

In this paper, I focus on the case of a robot that is portrayed as the "the world's first ultra-realistic humanoid AI robot artist" (retrieved March 21, 2020 from ai-darobot.com). It was engineered by the Cornish robotics company Engineered Arts and further by a team from Leeds and Oxford University that developed the robot's bionic hand [15]. The curator of the project is Lucy Seal. Ai-da has been described as "the brainchild" of Aidan Meller, a gallery director and art dealer from Oxford [16]. Reportedly named after Ada Lovelace, ${ }^{2}$ the robot can independently create unique artefacts using traditional tools, such as pencils. Ai-Da tends to be invested in drawing portraits of people by using the cameras in its eyes and its bionic hand developed by the research team at Oxford University. The robot also participates in the production of paintings.

In terms of appearance, Ai-Da's body design communicates using the established iconic standards presented on film and media, as well as intertextually with other humanoid robots made in research laboratories, such as Hiroshi Ishiguro's Geminoids, University of California San Diego's Kokoro and Hanson Robotics' Sophia. Unlike its hyper-realistic silicone face, Ai-Da's torso and hands have wiring and pneumatic parts exposed, though nicely arranged in a human-like form, with moulded transparent shells that form the chest and hips. When the robot wears a garment, the clothes drape on its body as they would on a human.

Currently, the dedicated website provides little information about the robot. To find more information and to gain access to the web gallery with Ai-Da's drawings and paintings, the user needs to "join [the] Ai-Da online movement" (ai-darobot.com). It is unclear what this means, other than obtaining the visitors' identities.

Ai-Da has been chosen as a case study for several reasons, as follows:

(a) The embodiment of the robot, with its recognisable facial semiotics, creates space for simulacrum and evocative iconology.

(b) The fact that Ai-Da has a supposedly female appearance opens a series of questions about gendered social robots.

(c) The robot is presented as an "artist", prompting questions about the so-called creative robots [17] and the connection between the embodiment and agency, serving the purpose of an "electronic personhood" ([18], p. 8).

(d) Using the opaque word movement in the knowledgesharing context, the website politicises communication from the very beginning using the barrier of selective access.

Taking these cited reasons into account, I argue that the semiotics behind this robot's actions and embodiment, coupled with its situated presence, belong to the transhistorical approach. Here, I refer specifically to Andreas Broeckmann's considerations of transhistorical understanding of "art", ${ }^{3}$

\footnotetext{
2 Ada Lovelace was an English mathematician who lived in the mid19th century and is famous for her contribution to Charles Babbage's mechanical computer, the analytical engine. Lovelace is considered one of the first computer programmers.

${ }^{3}$ I am fully aware that the term "transhistorical" is used in other research fields, such as History, Anthropology, and specifically, Memory Stud-
} 
although I am extending the term to the broader communicational strategies used to build the discourse about this robot. With its aim of setting some fixed benchmarks when evaluating art and being ultimately against cultural relativism (see, e.g., [20]), the transhistorical approach seeks to establish a timeless value in art history, a normative approach to originality, as well as operates within a hierarchical system of experts and artists-as-creative-individuals (for a version of the Romantic stance artist-as-genius, see $[1,21])$. In essence, the transhistorical approach tends to disregard the fact that the notion of "art"- the very nature of it, and the role it plays in society-shifts over time, depending heavily on cultural, societal and economic factors. As a result, some complex historical ideas and contexts may get "flattened"and simplified. As I argue in the Conclusion section, the strategy of presenting Ai-Da through the prism of this tradition is less than optimal, as it positions the robot with a repository of fixed, predefined meanings that reinforce myths about machines [1].

\section{Note about the method}

As mentioned, this paper uses discourse analysis to analyse the communication surrounding the Ai-Da robot. Broadly speaking, "discourse is a particular way of talking about and understanding the world (or an aspect of the world)" ([22], p. 12). Although there are many branches of discourse analysis, all of them accept a common denominator that the language used to interpret phenomena, identities, and social relations is never neutral —on the contrary, language plays an active role in creating and changing them (ibid, 12). In this way, beliefs and norms are disseminated and reproduced in a society, subsequently shaping attitudes and imaginaries ([23], p. 146). Michel Foucault emphasised the link between discourse and power: those who are in a position of power, have easy access to outlets of public discourse, thus shaping public opinions (ibid, 146). This qualitative method has been chosen for two reasons: a) there is still a limited amount of media messages about Ai-da; and b) in terms of presentation, the robot is almost always placed within a carefully designed décor (Victorian salon, atelier), making it an interesting case study. I am aware that the communication efforts of Ai-da team may change over time, as the robot gains progressively more advanced skills.

ies: for example, one can discuss "transhistorical and transgenerational trauma" (see: [19]). My use of the term, however, is tied to Broecmann's analysis above and is rooted in the field of Art History.

\section{Short history of machines engaged in a cultural production}

The last century as seen many artworks have been produced by machines [24,25]; for example, Jean Tinguely's painting machine, Méta-matics, was already introduced in the 1950s. During the same period, Nicholas Schöffer and Nam June Paik also produced autonomous systems [26,27]. Since then, the art public has witnessed several drawing robots, notably Leonel Moura's [28] swarm painting robots, Patrick Tresset's Six robots named Paul (2012) [29], Robotlab's appropriated KUKA arm, and others.

However, the idea behind machines that participate in the production of cultural artefacts has been around for centuries (for a detailed account on Hellenic and medieval mechanical automata, see: ([30], p. 331). Even if the production processes did not include mechanical agents, there were artistic attempts to reduce the artist's decision-making to a pure drive-as shown by the Dadaists in the 1920s [31]. The idea of automation (automatic drawing or writing) represented pure non-agentic agency. Producing an artwork that was not guided by artistic intention was the goal. As André Breton wrote in his First Manifesto of Surrealism: "SURREALISM, n. m. Pure psychic automatism by means of which one intends to express, either verbally, or in writing, or in any other manner, the actual functioning of thought. Dictated by thought, in the absence of any control exercised by reason, free of any aesthetic or moral concern" ([32], p. 19). Originating from the Dadaist movement, Breton's regimen of automated creativity served as a critique of the principles of logic and reason celebrated by the capitalist society. Following the same method, surrealism aimed to remove intention from the creative process and to liberate "free thought" [33]. The legacy of Dadaists and Surrealists taught generations of artists to rethink the creative process itself and to challenge the artist-as-genius myth.

Two of the most famous mechanical automata-The Musical Lady and The Writer - are functional to this day, made by Pierre Jaquet-Droz in the 1770s. These 18th-century automata were unique in the sense that, aside from their meticulously crafted mechanical bodies, they were producers of culture. Seated in front of a clavier, The Musical Lady would press down the individual keys with its fingers, playing one of the six compositions for which it could be programmed. Additionally, the automaton's torso would subtly sway during the performance, as well as rise and fall, resembling breathing movements. The Writer was capable of writing a number of messages, including Rene Descartes' famous philosophical statement: "I think, therefore I am" (Cogito, ergo sum), apparently in response to Descartes' and La Mettrie's concerns about the problem of movement. The automata were crafted with care and equipped with wigs and 


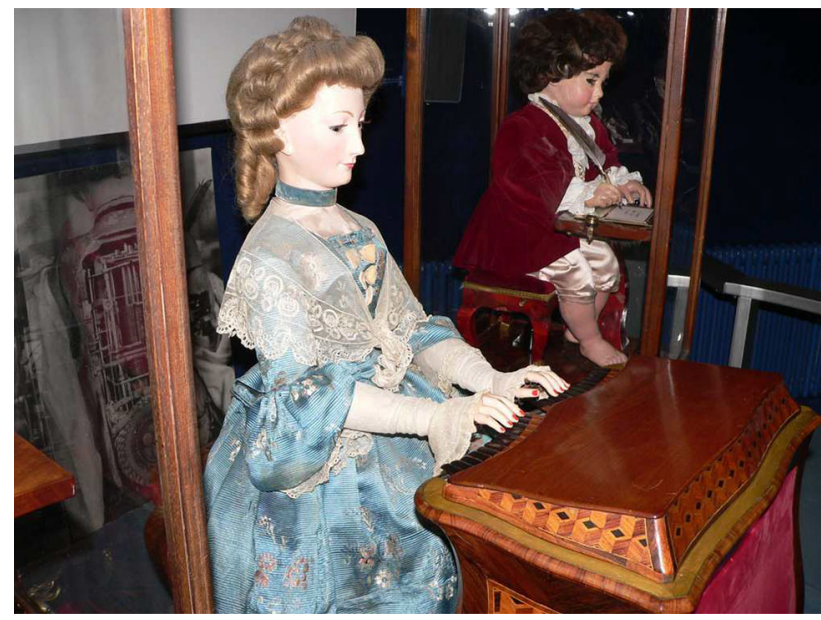

Fig. 2 Jaquet-Droz automata, Musée d'art et d'histoire de Neuchâtel", by Wikipedia user Rama is licensed under Creative Commons Attribution-Share Alike 2.0 France

real clothes to deliver the perfect mimesis of the human artisanship [34].

It is no wonder, then, that these first mechanical humanlike automata, which seemed to possess special skills, were perceived as ingenious and contributed to the philosophical debates of the time. "The automata represented the utopian promise of a human reason that was capable of both deciphering and mastering the laws of nature, a pursuit that found its ultimate expression in the attempt to create artificial or mechanical life" ([34], p. 31). It was the Baroque period that introduced machines as objects of wonder; they were appreciated for their form, regardless of their function ([30], p. 390). The principle of reason that belongs to man, a being superior to other creatures and a master of any complex machinery that society produces, had been the dominant idea of the period (influenced not only by the New Testament but also by thinkers, such as René Descartes). Several decades prior, the English philosopher Thomas Hobbes emphasised that civil peace would best be achieved through commonwealth, which should be thought of as an "artificial person", whom he named Leviathan [35]. Even if only presented as a metaphor, the idea around the artificial being that serves the interests of humans has been nourished in Western thought for centuries.

\section{Individuation}

In recent decades, advances in science and narrow AI have been showing results, resulting with social robots that are becoming progressively more sophisticated in calculating specific tasks. Sometimes these robots come up with unexpected solutions (as demonstrated by Alpha-Go in a match against Lee Sedol) ([36], p. 54).
The affordance of social robots that seems to be particularly alluring for the general public is a simulation of some form of communication. In such interaction, the social robot might appear as an electronic persona of sorts, a point to which I will return later. When the robot is being exhibited to the public (far from the testing lab, its natural habitat of sorts), given a name and a personal pronoun - a set of discursive strategies are put in place, which would serve the process I'll refer to as the individuation ${ }^{4}$ of a robot. The most famous example is the robot Sophia (Hanson robotics), which received Saudi citizenship in 2017, and whose creator Ben Goertzel on one occasion presented the robot as being "basically alive" due to its supposedly high level of AGI (Artificial General Intelligence) [38]. My aim here is not to calibrate the presence (or absence) of AGI in a social robot; instead, I am interested in the narratives that circulate around the robot, the fantasies and imaginaries they provoke, and in particular, what is left out of the picture when a social robot is being presented to a general audience.

Individuation happens when the discourse surrounding the social robot undermines or disregards the labour of associated humans that make the robot capable of performing a certain action. In most cases, those humans are the ones that work closely with the robot: engineers, designers, scientists, artists, etc. Individuation feeds the fantasy of robot's autonomy/independence/AGI — and can come directly from the creators of the robot, or arise within the media apparatus that covers the story about the robot.

Joanna Zylinska notes that advances in AI research marked a resurrection of the myth of the robot as the human's other ([39], p. 28). She criticises this approach, primarily due to its positioning of the human as a non-technological entity, involved in the "eternal battle with tekhne" (ibid, 29). Similarly, Andreas Broeckmann claims that "whenever the word 'machine' is uttered, this figure of speech constructs the relationship between human and the technical object within that mythical structure, as binary, antagonistic, and ontologically differentiated" ([1], p. 5). The myth contributes to the popular narratives that machines may "take over" (e.g. [40]), disregarding the historical presence of machinic devices in people's lives.

The human is, and has always been, a technological being - and the history of humankind is inseparable from the history of tools and apparatuses that were at our ancestors' disposal. Therefore, much replicated and reinforced man vs. machine discourse tends to gloss over the fact that this binary is often too simplistic and superficial. In line with this argument, Karen Barad reminds us that humans and machines "differentially emerge and are iteratively reworked through

\footnotetext{
4 The term "individuation" that I am using here should not be confused with Gilbert Simondon's understanding of "individualisation" (of technical objects) [37].
} 
specific entanglements of agencies that trouble the notion that there are determinate distinctions between humans and nonhumans" ([41], p. 239). Barad sees the notion of agency first and foremost as a relation, a process transformative for all parties involved. For example, a scientist who experiments with a robot enters this transformative space in the process of the construction of a robot, programming, tests, and so on. The robot, on the other hand, is being transformed through trial and error, inclusion of new data, change of hardware, etc. This exchange is a fluid process, which Barad names "intra-action" (ibid, 240). Intra-action is a material-discursive practice, which is causal, nonlinear and nondeterministic. Intra-activity rejects the notion of a stable, monolithic human subject and rigid divisions between humans and non-humans. It is also worth mentioning that the monolithic view on humanity disregards individual differences and operates within the realm of an imagined "typical" person (with the risk of excluding persons with mental and physical disabilities; see [42]).

\section{Drawing robots}

Some authors refer to robots that draw, paint or create music as "creative robots" [17,21]. The question about the creativity of artificial agents has initiated a heated debate [21,43-46], leading to many interpretations. For example, Coeckelbergh summarises various approaches to machine creativity, such as objective versus subjective views, collective agreement/institutionalisation, and process-oriented versus outcome-oriented approach [21]. He poses the question of whether we can observe robot creativity in its own right, aside from comparisons with humans. An illustrative point is outlined in Margaret Boden's book The Creative Mind: Myths and Mechanisms, where she questions if machines can be really creative, as opposed to just appearing as such (emphasis: Boden) ([44], p. 7). Most of these approaches attempt to determine an "authentic" creativity of machines, instead of just mimicking "human" creativity. In response to these dilemmas, Jan Løhmann Stephensen notes that such dichotomy assumes a "human" creativity to be a quintessential attribute of our species, something essentially pre-technological [47]. Stephensen makes an argument that there is no such thing as a solely human creativity, and that the very concept of creativity, now embraced by capitalist forces, is becoming increasingly political (ibid).

On a flip side, a notable detail about the discourse around so-called "machine creativity" [48]—as opposed to the human creativity mentioned above-is the tendency to observe the machine out of context. In my view, the question of creativity (if we were to use the term) only makes sense within the material-semiotic system that the robot is embedded into. This is, I believe, what Lucy Suchman refers to when she mentions that a "robot is infused with its inherited materialities" and "the labour of affiliated humans" ([11], p. 119). Acknowledging this, we should rather observe a creative potential of human-technical assemblages as a model of co-creation and meaning making, as Katherine Hayles suggests ([36], p. 52).

In order to avoid ambiguities and unwanted connotations, I will refrain from the attribute 'creative' and instead use descriptive verbs such as 'drawing', 'painting', etc. Johanna Seibt claims that the use of common verbs for human capacities ("teach", "observe", "greet" etc.) to describe robots' actions is questionable: she refers to it as the "intentionalist vocabulary": such vocabulary includes verbs that according to our common conceptual conventions imply consciousness, feeling, intentionality, etc., which may be deceptive for the human observers, especially in the context of experimental studies." ([49], p. 135). Seibt invites to a more rigorous vocabulary, that is not troubled by speciesism [50]. Hence, I refer to Ai-Da as a "drawing robot", since that is a literal description of this robot's activity.

In the following paragraphs I will demonstrate how the model of individuation of the machine works within the discourse embraced by Aidan Meller, the person behind the Ai-Da project:

The Ai-Da newsletter claims:

"Ai-Da is the world's first ultra-realistic humanoid AI robot artist capable of drawing people from life using cameras in her eyes, and a pencil in her left robotic hand. She creates artwork based on Professor Margaret Boden's philosophical definition of creativity — that it must be novel, surprising and of societal value" (December 9, 2019 issue).

The quote above shows the intention of an external validation of the robot's creativity. Ai-Da is not the first robot that can draw portraits of people (Patrick Tresset's robots can do that as well). What differentiates Ai-Da from the other creative robots is its anthropomorphic body (presented as "ultra-realistic"), and this attribute has been emphasized in the promotional material (ai-darobot.com). The robot's anthropomorphic design is treated as a transformative feature; its silicone face stretched over the machinic parts is evocative, granting the robot a personal pronoun ("she"). The problem of course, lies in the affective nature of the encounter between a human and an anthropomorphic robot: as Sherry Turkle noted, the robots "push our Darwinian buttons" ( [61], p. 3), stoking imaginaries about homo mechanisma, and provoking ideas about artificial identities. (Miles, cf. [50], p. 2).

We can find another effect of the individuation discourse and intentionalist language in the description of robot's activities. Within the right context, the robot can occupy the position of the artist (as part of a human-non-human assemblage), and actively participate in the production of an artwork (such as aforementioned Leonel Moura's robots, 
Patrick Tresset's Six robots named Paul, or Robotlab's adapted industrial robots). To borrow Hayles' term, the robot is involved in a form of a collaborative assemblage with its human counterparts, even when the robot's production (an actual drawing or a painting) is done solely by the robot or AI. See, for example, Harold Cohen's reflections on his collaboration with the "painting machine" Aaron: the program would come up with some unexpected solutions, but there are aspects that Cohen would have control over (how quickly the dye would dry, for example). Therefore, Cohen used the word "dialogue" to describe the collaborative process between himself and Aaron ([51], p. 286).

However, there is a pitfall that needs to be acknowledged: moving from the description of activities (the robot draws / the robot participates in the artistic activity) into the language of identity (the robot is an artist), whilst failing to acknowledge the collaborative aspect with a human artist, represents a rather careless translation of human experiences into a machine. The profession represents a complex intertwining of education, experience, knowledge, relationships, and value production. Applying the same concept to a machine reduces this concept to a single-channelled activity (see, e.g., Hans Moravec's use of the term "robot surgeon", [52]). Since the word artist carries with itself a surplus of meaning, it can be then used strategically — in the case of Ai-Da, this surplus of meaning is used to establish a transhistorical continuity, by connecting the production of the robot with verified iconic figures, such as Picasso (see: [53]).

The transhistorical approach tends to adapt the discourse in a such a fashion as to highlight the points of history that are relevant for the narrative, and thus to obscure the intervals and persons that are supposedly irrelevant for that same narrative. The transhistorical philosophical view observes the artworld as a somewhat monolithic and overtly coherent institution. It tends to ignore the turbulent history of modern and contemporary art, filled with incidents and perceived as sacrilege. Think, for instance, about the shock that Edouard Manet's Olympia caused to the Paris Salon in 1865, Marcel Duchamp's Fountain in 1917 and Viennese Actionists in the 1960s.

It is no wonder, then, that discourses surrounding drawing robots in most instances mention only a few, "established" historical figures, such as Leonardo Da Vinci, Vincent Van Gogh, and Pablo Picasso [53]. Meanwhile, the transhistorical discourse is quick to announce the "newness" and "uniqueness" of the drawing robot, ignoring various machines and robots that have been participants in the artworks throughout the 20th century, and where one of the dominant discourses was indeed the one about human engagement with tekhne [54].

Finally, I want to acknowledge the fact that much of the existing literature that analysed the output and processes of drawing robots (as well as those that compose music) focused on the question of intentionality, as one of the pillars of the process of creation, and one of the central characteristics of an artwork. Some authors have argued that, since robots do not intend to participate in the production, the output cannot be considered an artwork. The approach that I am taking-drawing largely from the Science and Technology Studies (STS) — does not position the robot as a sole actor in the activity of drawing/creative production. Since robots and humans are both involved in the intra-action and form a human-machinic assemblage, the question of the intentionality of the machine is not relevant for the output, which is an artifact/artwork (depending on the cultural context).

\section{The body of a machine}

When analysing the corporealization of a robot ([55], p. 142), we need to consider its historical and cultural specificity ([56], p. 317). According to Haraway, corporealization refers to the interaction practices between humans and nonhumans in the "distributed, heterogenous work process of technoscience" ([55], p. 142). As a result, the bodies that are being created are historically-specific material-semiotic bodies (p. 143). Furthermore, her term figuration refers to the extended layers of meanings and significations that extend the literal scope of the body. They are performative images that can be inhabited (p. 179).This way, Haraway looks beyond the material presence of the body, observing it as a larger assemblage of meanings, relationships and symbols that surround it, whilst acknowledging its agency. The body is never just a body.

Judith Butler has addressed this as well: "Not only did bodies tend to indicate a world beyond themselves, but this movement beyond their own boundaries, a movement of boundary itself, appeared to be quite central to what bodies 'are"' ([57], p. 3). Whether organismic or not, the bodies perform, and this performativity refers to the "reiterative and citational practice by which discourse produces the effects it names" ([57], xii). For example, heteronormativity is a direct effect of this mechanism, which perpetually reinforces itself and by doing so becomes normative, natural and traditional.

On one hand, humans actively perform their gender, and in this performance, gender displays its dynamic nature. On the other hand, robots perform fixed and historically specific gender imaginaries. In a sense, it could be argued that the word "gender" is not fully appropriate when discussing machines, due to the fluid nature of this practice that becomes rigid and limited when superimposed to the anthropomorphic robots like Ai-Da. As Knox observes, "the robots' genders are fabricated, but they are passive and polarized" ([58], p. 137). Since the robots are devoid of a nuanced gender performativity, they come across as uncanny. 
Whilst the robotic bodies reveal such imagined behaviours, they obfuscate a plethora of hidden mechanisms and relationships. Returning to Suchman's observations when she writes about "truncated labours" of affiliated humans-the invisible laboratory work is invested in making the robot, presenting it in a proper way and putting it on display-to present the corporality of this "subject object" ([6], p. 119). Suchman refers to a robot as a subject object, because it is deliberately individuated, presented as a "model in (organism)" (p. 121) as opposed to a body of a laboratory mouse, whose corporality is standardised, replicated and scaled, devoid of any individuality. $^{5}$

The corporality of the robot, being a figure at the crossroads between science and fiction $[59,60]$, is often influenced by the popular media aesthetic. In the Western context, the adopted media aesthetic of highly popular films tends to replicate itself into other media products, as seen in the famous example of the appearance of Machinenmensch Maria in Fritz Lang's film Metropolis (1927) and the subsequent design of the robot C-3PO in the Star Wars franchise. Intertextual iconic referencing can also be found in the corporality of the robots featured in the films I, Robot (2004) and Ex Machina (2014). The narratives and the visual signifiers shape the public imagination about robots, especially anthropomorphic robots, that have the appeal of a Narcissus image. However, the evocative quality of robots ([61], p. 3) is not limited to the moving pictures. The broader realm of public imaginaries ([62]) is influenced by various media, as well as material culture. Consider, for instance, the endless replications of square-headed robots on children's bedsheets, T-shirts and mugs.

The inspiration behind these stylised robotic bodies is found in visual arts and literature. Eduardo Kac observes that artists are exploring boundaries and challenging popular understandings of what a robot is-focusing on the ethical, societal and political implications of newly adopted technologies ([63], p. 2). Acknowledging the legacy of artistic work in researching robotics, the director of the Intelligent Robotics Laboratory Hiroshi Ishiguro remarks, "Artist[s] and philosophers are very important collaborators in the next [generation robots]. Why art? All engineering is coming from art" ([14], p. 5).

As I have mentioned, Ai-Da has a hyper-realistic silicone face and an exposed mechanical body. Such a hybrid approach in the design of Ai-Da serves two purposes. On one hand, it could be viewed as an attempt to avoid the uncanny valley effect [8], although the hybrid design causes the opposite effect in some people, who perceive the robot as even more uncanny if the inner mechanics are exposed and complemented with a hyper-realistic face.

\footnotetext{
$\overline{5}$ For another useful discussion about laboratory mice, precisely oncomice, see [55].
}

On an ontological level, the replaceability of the body parts of an anthropomorphic robot is both fascinating and grotesque. As Bakhtin writes: "The grotesque body is the body in the act of becoming. It is never finished, never completed; it is continually built, created, and builds and creates another body" (cf. [64], p. 114). We may see a parallel in the example of French artist ORLAN who throughout her career delineated this very mechanism with her own biological body. She is famous for her use of plastic surgery to repeatedly transform her face, treating it as a platform open for change, rather than a fixed iconic feature. Her lifelong project challenges the political presence of the female body, stereotypes around female beauty and its social meaning. By doing so, she challenges a "body in the act of becoming" ([65], p. 18). ORLAN displayed the robot ORLANOiDE at the Artistes et Robots exhibition at Grand Palais, Paris in 2016.

Similar to Ai-Da, ORLANÖiDE also has a meticulously crafted face, made in ORLAN's likeness, in contrast to its mechanical body. The full title of the piece is Streap-tease électronique et verbal (2017), where ORLAN continues her artistic pursuit in questioning the social, traditional, religious and political status of the body ([66], p. 186); however, in this work, the technologies that may modulate/reconstruct/reinvent the body are even more strongly emphasised. In ORLAN's work, the human body is not opposed to the body of the machine; the human body is already machinic, as it were. ${ }^{6}$

The point that will be obvious to any visitor of the gallery space where ORLANOiDE is exhibited is the question of gendered robots, the complex set of meanings implied with this work that fits like a puzzle in ORLAN's lifelong project. The decision to provide ORLANOiDE with an anthropomorphic face comes from ORLAN's transhumanist position in which the face is a modular platform. In contrast, AiDa's silicone face tells a different story; it is not there to recognise the machinic in a human but quite the opposite- - to obfuscate the machine behind a human-looking face. Even though its machinic parts are exposed, Ai-Da's face/mask gives it the special status is an individuated subject object [6]. We can note a rather playful address of this point in Aidan Meller's presentation of Ai-Da at the Ars Electronica 2019 festival, when he explained that the reason behind Ai-Da's anthropomorphic appearance lies in the team's deliberate intention to create a persona. For the reference, I will briefly remind the reader about the etymology of this term: the original meaning of the Latin word "persona", came into English in the thirteenth century and meant "a mask used by the player" ([69], p. 232), but later became a general word for

\footnotetext{
6 A more detailed analysis behind the statement that humans are, in essence, machines, can be found in [67]. Consider also a much older text, "Are we automata?" [68].
} 
the human being; notably, Carl Jung used the word persona to refer to the outward social role, a function of the relationship ([70], p. 156). I use this latter definition to interpret Meller's words below. Meller emphasizes the difference in audiences' attitude toward a computer that produces artworks, and an embodied, anthropomorphic robot that does the same thing. As he said, "the persona of the artist is very important to understand the interpretation of the artwork itself" [71]. Yet this epistemological shift nurtures a hidden fallacy: it claims that, precisely because the robot has recognisable features (in this case, the features of a woman), it allows for the tapestry of projections that indeed allow it to become the figuration of those projections. This narrative tries to convince the viewers that Ai-Da is a persona due to its anthropomorphic appearance; furthermore, it is an artist, because it utilises the capabilities that enable it to produce an artefact and serve the discourse of individuation.

In the context of public presentation of Ai-Da, its introduction as a persona seems to serve two interconnected purposes: a) On the one hand, it individualises this particular machine, as opposed to other machines that never enter the domain of a dialogic space; and b) It offers a romanticised, but unexplored idea that this robot possesses a form of subjectivity. What would have happened if the team behind the design of the robot decided to reject the idea about this robot's anthropomorphic appearance, but kept the reference to Ada Lovelace? Would this robot still be perceived as a persona? Meller's remark above seems to infer that such a robot would be less marketable to the general public. Yet the question remains: would the interpretation the artwork have changed if the robot had not been presented as a persona? This is another example of the mythologisation of technology, wherein the narrative about the (fictional) persona of a machine is used as part of a promotional strategy. As mentioned, the robot has been advertised as the "the world's first ultra-realistic humanoid AI robot artist" - therefore, neither "the first ultra-realistic humanoid robot" nor "the first robot artist", but a combination of the two. At the same time, a careful wording capitalises on the presumed novelty of the whole, giving the impression that Ai-da is the first robot involved in a cultural production.

\section{Ironical revisitation}

Altogether, the robot's anthropomorphic design, coupled with an assemblage of tropes serves as a site of ironical revisitation where the creators of the historically inspired spectacle treat historical facts in a rather loose or even playful manner ([72], p. 142).

In the case of Ai-Da, the historical figure of Ada Lovelace is used only as a pretext [72], p. 141), which is then coupled with stereotypical tropes: Ai-Da's working shirt is stained with paint: ${ }^{7}$ Ai-Da and Meller are seated in an interior furnished with furniture from the Victorian era, and so on. Other promotional photographs represent $\mathrm{Ai}-\mathrm{Da}$ as a lonely figure in a Victorian atelier, surrounded by its drawings and paintings. This carefully chosen semiotic contributes to the myth of a machine, as well as to the myth of a lone genius artisteccentric, but ultimately apolitical. This familiar trope might communicate well with the general audience, but it will teach nothing about the the political role of artists who were often in the frontline for social change.

Furthermore, the specific design choices and technical arrangement surrounding anthropomorphic robots should be taken into account. The human-like appearance of the robots taps into the pre-existing categories of class and power struggles that are mirrored in the technological artifice. From one side, the technology can enhance power, authority and privilege since the very design of such technology can "produce a set of consequences logically and temporally prior to any of its professed uses" ([13], p. 30). This collection of choices is purposely put in place to serve a certain narrative, and the members of the audience are expected to channel their understanding and their imaginaries within this predefined framework. The period during which Ada Lovelace lived (also represented in Ai-da's promotional material) is a period of the expansion of the British Empire, during which it solidified its hegemonic power. Through this act of revisitation, the Ai-da project may enact a feeling of a national pride, progress, something that Paul Gilroy would describe as "postimperial hungering for renewed greatness" ([73], p. 103).

Furthermore, the Ai-Da project re-inserts and revalidates the breakthrough discoveries in the earliest days of cybernetics; the robot made portraits of established British scientists (Charles Babbage, Alan Turing, Ada Lovelace) and itself, as well as those of Karel Čapek and Leonardo da Vinci. Within a transhistorical narrative, the linear interpretation of progress is the preferred nexus, praising remarkable historical figures; with an emphasis on that linearity, the Ai-Da project positions itself in the company of the "Greats." Such a narrative tends to omit the fact that science is a collaborative process, involving relationships, correspondence and validation procedures. As humanoid robots are individualised and naturalised [6], as well as put on display in a highly staged and choreographed manner, this mythical discourse may be somewhat deceptive for the less-informed members of the audience [74]. As shown by Simon Penny, people tend to use their own experiences to interpret robots' actions, and some-

\footnotetext{
7 This is a description of how the paintings attributed to Ai-Da come to life: "Labels state that coordinates from Ai-Da's drawings are 'plotted onto the Cartesian plane and then run through AI algorithms.' The digital versions of the artworks were transferred on canvas, and overlaid with oil paint by artist Suzie Emery" [15].
} 
times, their expectations and projections do not match the actual capabilities of the robot. He writes that "any effective agent interface design project must be concerned with capitalising on the users' store of metaphors and associations" [77]. The criticism toward humanoid robots pertains, leading some academics to advocate against human-like appearance of the robot (e.g. [75]). Instead of advocating an outright ban of such a design, I want to emphasize the importance of multi-layered narratives, variety of perspectives, precise descriptions of robot's activities and realistic expectations of its performance. Last but not least, I do agree that promoting deceptive narratives about robots is unethical, even if it makes people happy or inspired (as demonstrated in this case study about care robots [76]).

\section{Conclusion}

In this paper, I have aimed to observe a specific anthropomorphic robot embedded in a broader realm of signifiers, relationships and materialities. Ai-Da's appearance and actions form an assemblage that interacts with other assemblages, such as cultural context, heritage, history and representational politics [12]. Robots are not culturally neutral [77]; the repository of meanings exists from the moment a robot enters a social context.

The promotion and branding of this robot touch on larger discourses, but leave them mainly unexplored. The insistence on Ai-Da's "firstness" and "uniqueness" shows partial ignorance about a broader realm of robots and AI used in cultural production and a lengthy history of machines invested in artistic endeavours [24]. The chosen strategy may reap some sensationalist titles in the media, but it does not contribute to the situated knowledge sharing.

What provoked me to start writing this paper in the first place was the set of strategies that seemed superimposedsuch as the use of evocative semiotics for the robot's face and its anthropomorphic body, as if to make it eligible for "electronic personhood" in light of its actions (within the framework of the imagined category of the artist). Would this robot be any less of a cultural agent if its body had to be designed "beyond anthropomorphism"? The fixation on transhistorical presentational tactics prevents this robot's full participation in the fluidity of culture, where meanings are negotiated and reconsidered ${ }^{8}$ [78]. Instead, the robot is

\footnotetext{
${ }^{8}$ Many humanoid robots have participated in artistic projects. For example, Hiroshi Ishiguro's robot Actroid-F participated in Elena Knox's project Comfortable and Alive (2014). Another example is Justine Emard's project Co(AI)xistence (2017), where the robot Alter interacts with the dancer Mirai Moriyama. Through different exposures, the socio-political presence of these robots are recontextualised and reimagined.
}

trapped in a patriarchal dream of a controlled environment belonging to the romanticised past.

Acknowledgements I would like to thank Bo Reimer, Erin Cory, Richard Topgaard, Anders Høg Hansen, and the three anonymous reviewers for their valuable comments and suggestions.

Funding The research is supported by the Strategy Group for EUCoordination, represented by Vinnova.

\section{Declarations}

Conflict of interest The author declares that they have no conflict of interest.

Open Access This article is licensed under a Creative Commons Attribution 4.0 International License, which permits use, sharing, adaptation, distribution and reproduction in any medium or format, as long as you give appropriate credit to the original author(s) and the source, provide a link to the Creative Commons licence, and indicate if changes were made. The images or other third party material in this article are included in the article's Creative Commons licence, unless indicated otherwise in a credit line to the material. If material is not included in the article's Creative Commons licence and your intended use is not permitted by statutory regulation or exceeds the permitted use, you will need to obtain permission directly from the copyright holder. To view a copy of this licence, visit http://creativecomm ons.org/licenses/by/4.0/.

\section{References}

1. Broeckmann A (2019) The machine as artist as myth. Arts. https:// doi.org/10.3390/arts8010025

2. Damiano L, Dumouchel P (2018) Anthropomorphism in humanrobot co-evolution. Front Psychol. https://doi.org/10.3389/fpsyg. 2018.00468

3. Ishiguro H (2014) Android Philosophy. In: Seibt J, Nørskov M (eds) Sociable Robots and the future of social relations. IOS Press, Amsterdam, p 3. https://doi.org/10.3233/978-1-61499-480-0-3

4. Nørskov M, Yamazaki R (2018) Android Robotics and the conceptualization of human beings: the telenoid and the Japanese concept of nature. In: Coeckelbergh M, Loh J, Funk M, Seibt J, Nørskov M (eds), Power, politics, and public space: proceedings of robophilosophy 2018/TRANSOR 2018. IOS Press, Amsterdam, pp 238-246

5. Schfield D, LeRoy L (2018) Representing robots: the appearance of artificial humans in cinematic media. J Art Hum. https://doi.org/ 10.18533/journal.v7i5.1345

6. Suchman L (2011) Subject objects. Fem Theor. https://doi.org/10. $1177 / 1464700111404205$

7. Fong T, Nourbakhsh I, Dautenhahn K (2003) A survey of socially interactive robots. Robot Auton Syst. https://doi.org/10.1016/ S0921-8890(02)00372-X

8. Mori M (2012) The uncanny valley: the original essay by Masahiro Mori. IEEE Robot Autom Mag 12:1-6

9. Kim M-S, Kim E-J (2012) Humanoid robots as 'The Cultural Other': are we able to love our creations? Ai Soc. https://doi.org/ 10.1007/s00146-012-0397-z

10. Koh JTKV, Dunstan BJ, Silvera-Tawil D, Velonaki M (eds) (2015) Cultural robotics. First international workshop, CR 2015 Held as Part of IEEE RO-MAN 2015 Kobe, Japan (August 31, Revised Selected Papers) 
11. Suchman L (2007) Human-machine reconfigurations: plans and situated actions, 2nd edn. Cambridge University Press, Cambridge

12. Saunders R, Gemeinboeck P, Lombard A, Bourke D, Kocabali B (2010) Curious whispers: an embodied artificial creative system. In: Procedia Comput Creat, ICCC-10, pp. 100-109

13. Winner L (1985) Do artifacts have politics? In: MacKenzie D, Wajcman J (eds) The social shaping of technology: How the refrigerator got its hum. Open University Press, Milton Keynes, pp. 26-38

14. Knox E (2017) Degrees of freedom. Fibreculture. https://doi.org/ $10.15307 /$ fcj.28.204.2017

15. Ambrosio C (2019) An AI-driven artist's exhibition hints at, but never fully explores, the ethics of algorithms. Science. https://blogs.sciencemag.org/books/2019/07/01/unsecuredfutures/. Accessed 30 March 2020

16. Midas PR (2019) The World's first humanoid robot artist. https:// www.midaspr.co.uk/case-studies/worlds-first-ai-humanoidrobot-artist/ Accessed 30 March 2020

17. Gemeinboeck P, Arts E, Wales NS (2017) Creative robotics: rethinking human machine configurations. Fibreculture. https:// doi.org/10.15307/fcj.28

18. Jones R (2016) Personhood and Social Robotics: a psychological consideration. Routledge, New York

19. Onega S, del Río C, Escudero-Alías M (eds) (2017) Traumatic memory and the ethical, political, and transhistorical functions of literature. Palgrave Macmillan, Cham

20. Crowther P (2002) The transhistorical image: philosophizing art and its history. Cambridge University Press, Cambridge

21. Coeckelbergh M (2017) Can machines create art? Philos Technol. https://doi.org/10.1007/s13347-016-0231-5

22. Jørgensen M, Phillips LJ (2002) Discourse analysis as theory and method. Sage, London

23. Given L (ed) (2008) The sage encyclopedia of qualitative research methods, vols 1 and 2. Sage Publications, Thousand Oaks

24. Broeckmann A (2016) Machine art in the twentieth century. The MIT Press, Cambridge, Massachusetts

25. Dixon S (2004) Humanizing robots, returning to. Drama Rev 48(4): $15-46$

26. Neutres J (2018) De l'imagination artificielle. In: Dorléac LB, Neutres J (eds) Artistes et robots: au Grand Palais. Beaux-arts Editions, Issy-les-Moulineaux, pp. 10-13

27. de Smet E (2018) We are the robots. In: Dorléac LB, Neutres J (eds) Artistes et robots: au Grand Palais. Beaux-arts Editions, Issyles-Moulineaux, pp. 36-43

28. Moura L (2018) Robot art: an interview with Leonel Moura. Arts. https://doi.org/10.3390/arts7030028

29. Ch’ Ng E (2019) Art by computing machinery: Is machine art acceptable in the artworld? ACM Tran Multimed Comput Commun Appl. https://doi.org/10.1145/3326338

30. Eco U (ed) (2004) On beauty: a history of a western idea. Secker and Warburg, London

31. Hughes R (2013) The shock of the new. Alfred A, Knopf, New York

32. Breton A (2010) First manifesto of surrealism-1924. Manifestoes of surrealism. http://www.geraldhabarth.com/wvu/em/intro/fa12/ docs/projects/breton.pdf. Accessed 30 March 2020

33. Clancy R (1949) Surrealism and freedom. Am J Econ Sociol $8(3): 271-276$

34. Stephens E, Heffernan T (2016) We have always been robots: the history of robots and art. In: Herath D, Kroos C, Stelarc (eds) Robots and art: exploring an unlikely symbiosis. Springer, Adelaide

35. Hobbes T, ([1914], (1947) Leviathan, or the matter. Forme and power of a commonwealth ecclesiastical and civil. JJ.M, Dent, London
36. Hayles KN (2019) Can computers create meanings? A cyber/bio/semiotic perspective. Crit. Inq. 46(1):32-55. https://doi. org/10.1086/705303

37. Simondon G (2017) On the mode of existence of technical objects. University of Minnesota Press, Minneapolis, London

38. Vincent J (2018) Facebook's head of AI really hates Sophia the robot (and with good reason). The Verge. https://www.theverge. com/2018/1/18/16904742/sophia-the-robot-ai-real-fake-yannlecun-criticism. Accessed 4 February 2021

39. Zylinska J (2020) AI art: machine visions and warped dreams. Open Humanities Press

40. Pogue D (2018) Is art created by AI really art? Scientific American. https://www.scientificamerican.com/article/is-artcreated-by-ai-really-art/. Accessed 20 April 2020

41. Barad K (2007) Meeting the universe halfway: quantum physics and the entanglement of matter and meaning. Duke University Press, London

42. Siebers T (2010) Disability aesthetics. University of Michigan Press, Michigan

43. Besold TR, Schorlemmer M, Smaill A (eds) (2015) A computational creativity research: towards creative machines. Atlantis Thinking Machines, Osnabrück

44. Boden M (2004) The creative mind: myths and mechanisms, 2nd edn. Routledge, London and New York

45. Boden M (2011) Creativity and art: three roads to surprise. Oxford University Press, Oxford

46. Steinert S (2017) Art: brought to you by creative machines. Philos Technol. https://doi.org/10.1007/s13347-016-0230-6

47. Stephensen JL (2020) Artificial creativity, anthropocentrism and post-creativity-the political stakes. Artificial Creativity conference. November 19-20, 2020, Malmö

48. Miller AI (2019) The artist in the machine: the world of AI-powered creativity. The MIT Press, Cambridge, Massachusetts

49. Seibt J (2018) Classifying forms and modes of co-working in the ontology of assymetric social interactions (OASIS). In: Coeckelbergh M, Loh J, Funk M, Seibt J, Nørskov M (eds) Envisioning robots in society-power, politics, and public space/Proceedings of robophilosopy 2018/TRANSOR 2018. IOS Press, pp 133-146

50. Jones R (2017) What makes a robot 'social'? Soc Stud Sci 47(4):556-579

51. Boden M, Edmonds EA (2019) From fingers to digits: an artificial aesthetics. The MIT Press, Cambridge Massachusetts

52. Moravec H (1988) Mind children: the future of robot and human intelligence. Harvard University Press, Cambridge, Massachusetts

53. Stock M (2019) The new Picasso? Meet Ai-Da the robot artist, reuters (https://www.reuters.com/article/us-tech-robot-artidUSKCN1Q0001. Accessed 20 April 2020. https://www.reuters. com/article/us-tech-robot-art-idUSKCN1Q0001. Accessed 20 April 2020

54. Broeckmann, A (2020) Robots vs. machines. Artificial creativity conference. Malmö (19-20 November 2020)

55. Haraway D (2018) (2nd ed) Modest_Witness@Second_Millenium.FemaleMan_Meets( ${ }^{\text {TM }}$.Routledge, New York

56. Castañeda C, Suchman L (2014) Robot visions. Soc Stud Sci 44(3):315-341

57. Butler J (1993) Bodies that matter: on the discursive limits of 'sex'. Routledge, New York

58. Knox E (2015) 'Face Robots' onscreen: comfortable and alive In: Koh JTKV, Dunstan B, Silvera-Tawil D, Velonaki M (ed) Cultural robotics. First international workshop, CR 2015 Held as Part of IEEE RO-MAN 2015 Kobe, Japan, pp 133-142 (August 31, Revised Selected Papers)

59. Kakoudaki D (2007) Studying robots, between science and the humanities. Int J Hum 5(8):165-181

60. Romic, B (2018) Robotic art and cultural imagination. EVA Copenhagen 2018-politics of the machines. Elec- 
tronic Workshops in Computing (eWIC), British Computer Society. https://www.scienceopen.com/hosted-document?doi=10. 14236/ewic/EVAC18.48

61. Turkle S (2010) In good company? On the threshold of robotic companions. In: Wilks Y (ed) Close engagements with artificial companions: key social, psychological and design issues. John Benjamins Publishing Company, Amsterdam

62. Fritz A, Gehl RW (2016) Pinning the feminine user: gender scripts in Pinterests sign-up interface. Media Cult Soc 38(5):686-703

63. Kac E (1997) Foundation and development of robotic art. Leonardo 56(3):60-67

64. Nelson V (2001) The secret life of puppets. Harvard University Press, Cambridge, Massachusetts

65. Lovelace C (1995) Orlan: offensive acts. Perform Art J 17(1):13-25

66. Dorléac LB, Neutres J (eds) (2018) Artistes et robots: au Grand Palais. Beaux-arts Editions, Issy-les-Moulineaux

67. Brooks R (2002) Robot: the future of flesh and machines. The Penguin Press, London

68. James W, ([1879], (2003) Are we automata? Classics in the history of philosophy. https://psychclassics.yorku.ca/James/ automata.htm. Accessed 30 March 2020

69. Williams R (1976) Keywords: a vocabulary of culture and society. Fontana Press, London
70. Jung CG (2017) Psychological types. Routledge, New York

71. Meller A (2019) Introduction of the Ai-Da robot. Ars electronica festival

72. Eco U (1990) Travels in hyper-reality. A Harvest Book, San Diego

73. Gilroy P (2004) After empire: melancholia or convivial culture?. Routledge, London and New York

74. Boden M, Bryson J, Caldwell D, Dautenhahn K, Edwards L, Kember S, Winfield A (2017) Principles of robotics: regulating robots in the real world. Connect Sci. https://doi.org/10.1080/09540091. 2016.1271400

75. Breazeal CL (2002) Designing sociable robots. The MIT Press, Cambridge, Massachusetts

76. Sparrow R, Sparrow L (2006) Mind Mach 16:141-161. https://doi. org/10.1007/s11023-006-9030-6

77. Penny S (1997) Embodied cultural agents: at the intersection of art, robotics, and cognitive science. AAA Socially Intelligent Agents Symposium

78. Wajcman J (2004) TechnoFeminism. Polity Press, Cambridge

Publisher's Note Springer Nature remains neutral with regard to jurisdictional claims in published maps and institutional affiliations. 